\title{
The simulation of the diurnal cycle of convective precipitation over land in a global model
}

\author{
By P. BECHTOLD ${ }^{1 *}$, J.-P. CHABOUREAU ${ }^{2}$, A. BELJAARS ${ }^{1}$, A. K. BETTS ${ }^{3}$, \\ M. KÖHLER ${ }^{1}$, M. MILLER ${ }^{1}$ and J.-L. REDELSPERGER ${ }^{4}$ \\ ${ }^{1}$ European Centre for Medium-Range Weather Forecasts, Reading, UK \\ ${ }^{2}$ Laboratoire d'Aérologie, Observatoire Midi-Pyrénées, Toulouse, France \\ ${ }^{3}$ Atmospheric Research, Pittsford, USA \\ ${ }^{4}$ Centre National de Recherche Météorologique, Toulouse, France
}

\begin{abstract}
SUMMARY
In the context of the European Cloud Systems project, the problem of the simulation of the diurnal cycle of convective precipitation over land is addressed with the aid of cloud-resolving (CRM) and single-column (SCM) model simulations of an idealized midlatitude case for which observations of large-scale and surface forcing are available. The CRM results are compared to different versions of the European Centre for Medium-Range Weather Forecasts (ECMWF) convection schemes using different convective trigger procedures and convective closures. In the CRM, maximum rainfall intensity occurs at $15 \mathrm{~h}$ (local time). In this idealized midlatitude case, most schemes do not reproduce the afternoon precipitation peak, as (i) they cannot reproduce the gradual growth (typically over 3 hours) of the deep convective cloud layer and (ii) they produce a diurnal cycle of precipitation that is in phase with the diurnal cycle of the convective available potential energy (CAPE) and the convective inhibition (CIN), consistent with the parcel theory and CAPE closure used in the bulk mass-flux scheme. The scheme that links the triggering to the large-scale vertical velocity gets the maximum precipitation at the right time, but this may be artificial as the vertical velocity is enforced in the single-column context.

The study is then extended to the global scale using ensembles of 72-hour global forecasts at resolution T511 (40 km), and long-range single 40-day forecasts at resolution T159 $(125 \mathrm{~km})$ with the ECMWF generalcirculation model. The focus is on tropical South America and Africa where the diurnal cycle is most pronounced. The forecasts are evaluated against analyses and observed radiosonde data, as well as observed surface and satellite-derived rainfall rates. The ECMWF model version with improved convective trigger produces the smallest biases overall. It also shifts the rainfall maximum to $12 \mathrm{~h}$ compared to $9.5 \mathrm{~h}$ in the original version. In contrast to the SCM, the vertical-velocity-dependent trigger does not further improve the phase of the diurnal cycle. However, further work is necessary to match the observed $15 \mathrm{~h}$ precipitation peak.
\end{abstract}

KEYWORDS: General-circulation models

\section{INTRODUCTION}

The diurnal cycle of convection over land is of major importance for many aspects of climate studies, in particular via its strong modulation of the radiative budget by convective clouds, its resulting precipitation, and its control on surface temperature. It is primarily controlled by a change of vertical stability that arises as solar insolation heats the earth's surface, and subsequently the atmosphere through diurnal variations in the surface fluxes, leading to the development of convection. Over land, most observational studies show that precipitation tends to occur in the afternoon or evening. For example, observations from the Tropical Rainfall Measurement Mission (TRMM) precipitation radar (Lin et al. 2000) indicate a maximum rain rate at $15 \mathrm{~h}$. This is 3 hours earlier than the rainfall estimations obtained from infrared satellite observations by Yang and Slingo (2001) due to the time-lag between the heaviest surface precipitation and the coldest cloud tops. Over oceans, the maximum tends to occur during the night at $3 \mathrm{~h}$ according to in situ measurements of rainfall during the Tropical Ocean-Global Atmosphere Coupled Ocean-Atmosphere Response Experiment, again 3 hours earlier

\footnotetext{
* Corresponding author: European Centre for Medium-Range Weather Forecasts, Reading RG2 9AX, UK. e-mail: peter.bechtold@ecmwf.int
} 
than the maximum extent of cold clouds (Janowiak et al. 1994). Their results also confirmed the existence of shallower cumulus congestus clouds during the afternoon. However, regional characteristics such as land-sea contrasts, local orography, or mesoscale circulations can further modulate low-level convergence and, consequently, the timing of precipitation (Wallace 1975; Dai et al. 1999; Mapes et al. 2003).

The diurnal cycle of continental convection involves many coupled processes between the surface, the boundary layer, and the free troposphere such as surface exchange, turbulence, and convection and cloud-radiation interactions. In a generalcirculation model (GCM), all these processes are parametrized, so the ability of a GCM to simulate correctly the diurnal cycle is an important test of physical parametrization schemes. Although most of the GCMs reasonably predict the (monthly) mean rainfall, they fail to capture the broad pattern of the diurnal cycle of precipitation, with overestimated precipitation frequency and underestimated precipitation intensity (Slingo et al. 1992; Dai et al. 1999; Lin et al. 2000; Yang and Slingo 2001). As rainfall also occurs too early after sunrise, this suggests a too rapid response of the convective parametrization to the diurnal cycle in surface fluxes, indicating either a weakness in the convective triggering procedure or the turbulent and convective mixing of the atmosphere.

In the ECMWF Integrated Forecasting System (IFS), too early convective precipitation has also been reported, in midlatitudes close to local noon (Betts et al. 1998), and over Amazonia only a few hours after sunrise (Betts and Jakob 2002a). This error in the diurnal cycle of precipitation has been recently investigated by Betts and Jakob (2002b) with the aid of a single-column model (SCM) including interactive surface fluxes. They show that the SCM approach is useful to explore the response of the convection scheme to both idealized and large-scale forcing and suggest that the convective parametrization is the source of the error. However, the authors found it difficult to cure this problem, although they explored the sensitivity to the convective parametrization.

The purpose of this paper is to investigate the effect of some aspects of convection parametrization on the diurnal cycle of precipitation. The focus is on the triggering algorithm, as it plays an important role in the timing of precipitation. Four different mass-flux schemes are described in section 2, mainly different in the triggering, but also the effect of shallow convection closure is explored. Several authors (e.g. Betts and Jakob 2002b) speculate on the crucial role of shallow convection during the midday build-up of convection.

The European Cloud Systems (EUROCS) project selected the midlatitude case documented by Xie et al. (2002), because it has a clear diurnal cycle in precipitation and has only weak large-scale forcing. The SCM is forced by observed large-scale tendencies and surface fluxes. The SCM approach has the advantage that it can be compared directly to cloud-resolving model (CRM) simulations which were also performed for this case as part of the EUROCS project. Earlier work by Betts and Jakob (2002b) has demonstrated that the diurnal cycles as simulated by a SCM tend to give results that are consistent with those from the global model, so the SCM is a very useful and costeffective tool to study parametrization schemes. The single-column simulations with the four convection schemes are compared to the CRM simulations in section 3 and conclusions are drawn about the effect of the parametrization differences.

Finally, section 4 describes the results of global simulations using the ECMWF IFS with three of the four convection schemes. The purpose is to see whether the results from the single-column simulations are reproduced in the full three-dimensional (3D) context. The results are further evaluated by comparison with analyses, radiosonde data and observations from TRMM. 


\section{DESCRIPTION OF THE CONVECTION SCHEMES}

Two convection schemes are tested in the following: (i) the version of the convection scheme used operationally in the ECMWF model until January 2003 (hereafter EC), originally developed by Tiedtke (1989) and revised by Gregory et al. (2000), and (ii) the convection scheme adapted from Kain and Fritsch (1993) by Bechtold et al. (2001) (hereafter referred to as KFB). In addition, we have tested two modified versions of the EC scheme, called ECM (which became the operational ECMWF model on 14 January 2003) and ECS, which are detailed below. All four schemes are based on the same mass-flux formulation using a bulk cloud ensemble model, with a trigger procedure that determines the occurrence of convection and the type (deep, shallow, "midlevel' = elevated instability in frontal systems). This is followed by the computation of the updraught and downdraught properties and mass fluxes, and finally the convective tendencies that are adjusted following a closure assumption to control the intensity of convection.

Both the KFB and three EC schemes use a closure for deep convection based on the assumption that the convective available potential energy (CAPE) is consumed by cumulus convection over a given time-scale (set to 1 hour for both the SCM and T159 GCM runs, and to 20 mins for the T511 runs). In the three EC schemes, the initial downdraught mass flux at the level of free sinking is set to 0.3 times the updraught mass flux at the lifting condensation level (LCL), while in the KFB scheme using a precipitation efficiency of 0.7 gives a similar ratio of downdraught to updraught mass flux. However, the schemes differ in the trigger procedure and the entrainment coefficient, as well as in the shallow convection closure, as listed in Table 1, and also in the microphysical and numerical formulations of the bulk model.

The trigger procedure of the EC scheme computes the ascent for a surface parcel based on a simplified undiluted plume model. If cloud base is found while the incloud virtual potential temperature, $\theta_{\mathrm{v}}^{\mathrm{c}}$, exceeds the environmental value, $\bar{\theta}_{\mathrm{v}}$, by a certain threshold, cumulus convection is initiated and the first-guess cloud-top height is defined as the height where the value of the saturated moist static energy of the environment exceeds the cloud-base value. Then, a distinction between deep and shallow convection is made depending on the depth of convection; a convective cloud with depth exceeding $200 \mathrm{hPa}$ is considered as deep, otherwise it is considered shallow. A third type of convection, named mid-level convection, can be activated if neither deep nor shallow convection is found, when a model layer more than $500 \mathrm{~m}$ above the surface exists with the relative humidity exceeding $80 \%$, and where the large-scale vertical velocity is positive. The entrainment rate profiles for the final (second iteration) updraught computations are imposed between the cloud base and cloud top as computed in the trigger procedure. The entrainment rate for deep convection is split into a 'turbulent' part, $\epsilon_{\text {turb }}$, and an 'organized' part, $\epsilon_{\text {org }}$, the latter depending on the updraught velocity (Gregory et al. 2000). The value of the turbulent entrainment rate decreases from a value of $4 \times 10^{-4} \mathrm{~m}^{-1}$ at cloud base to a value of $1 \times 10^{-4} \mathrm{~m}^{-1}$ in the first $150 \mathrm{hPa}$ above cloud base. The turbulent entrainment rate of shallow convection is 2.5 times larger than the value for deep clouds.

In the ECM version, the trigger procedure of the EC scheme has been modified to compute a cloud-top height based on an updraught vertical velocity equation (Jakob and Siebesma 2003). The cloud top is identified as the level where the vertical velocity vanishes. The scheme first looks for shallow convection (with a cloud depth less than $200 \mathrm{hPa}$ ) by considering a strongly entraining parcel originating from the first model level above the surface with an initial temperature and moisture perturbation that is 


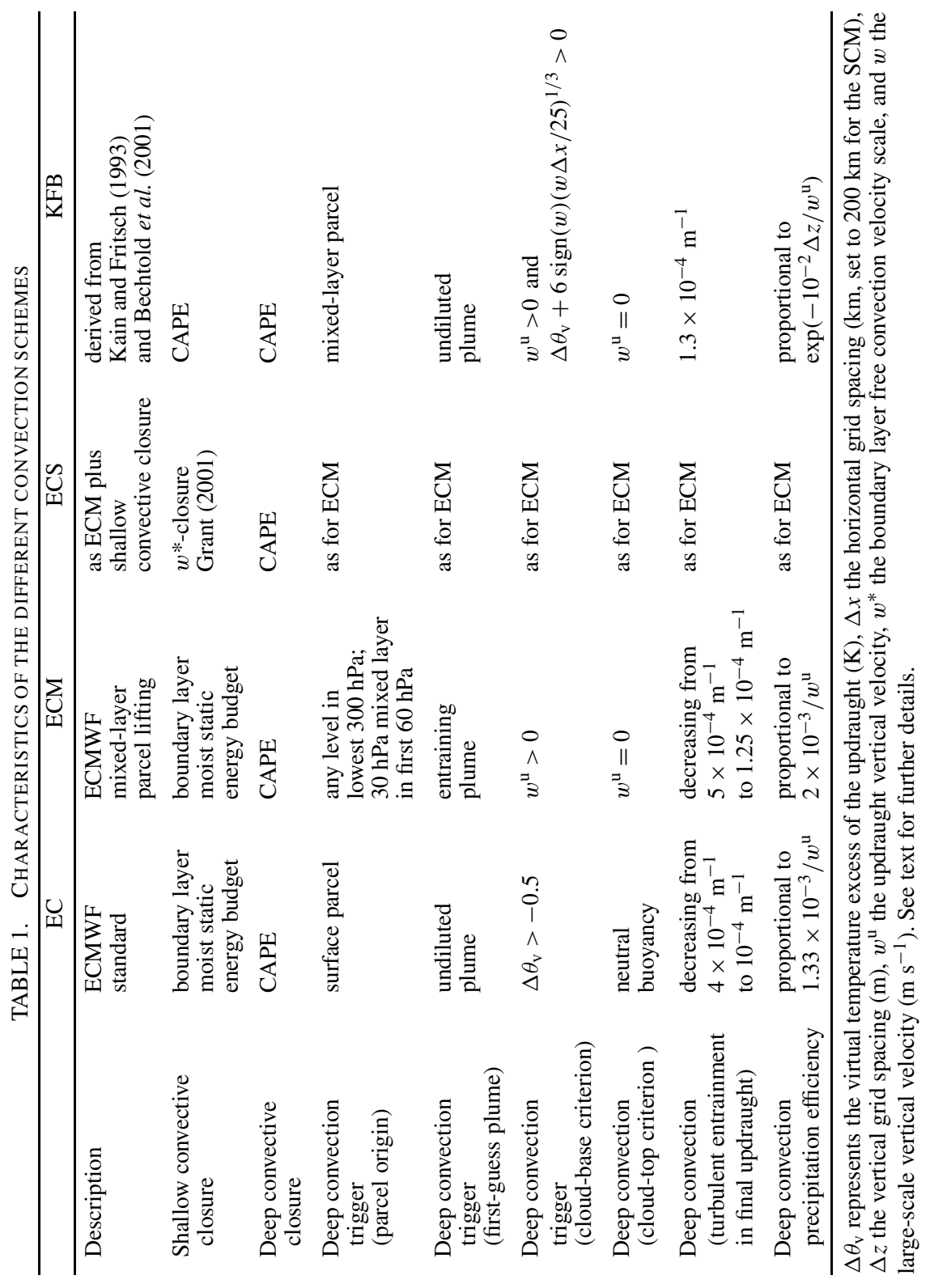


based on surface-layer similarity. Then the scheme looks for weakly entraining deep convection originating in the lowest $300 \mathrm{hPa}$ of the atmosphere, starting at the second model level above the surface. If deep convection is found (i.e. a cloud depth greater than $200 \mathrm{hPa}$ ), this solution replaces the shallow convection solution; otherwise the next model layer is tested. For model levels in the first $60 \mathrm{hPa}$ above the surface, a $30 \mathrm{hPa}$ layer average is lifted (with an initial temperature and moisture perturbation set to $0.2 \mathrm{~K}$ and $0.1 \mathrm{~g} \mathrm{~kg}^{-1}$ ), while above the first $60 \mathrm{hPa}$ (up to $300 \mathrm{hPa}$ ), model layers are lifted. No buoyancy test at cloud base is made; it is only required that the cloud-base vertical velocity of the parcel is positive. Furthermore, the ECM version uses a turbulent entrainment rate that is increased by a factor of 1.2 compared to the standard EC version, and a precipitation conversion factor that is increased by a factor of 1.5 (resulting in less liquid-water loading in the convective updraught and increased convective precipitation).

The trigger function of the KFB scheme is equivalent to ECM but it also tests for buoyancy at cloud base and adds a positive/negative temperature perturbation to the parcel based on the sign of the large-scale vertical velocity, $\bar{w}$ (Kain and Fritsch 1993). Therefore deep convection tends to be favoured/suppressed when the subcloud-layer large-scale vertical velocity is positive/negative. The trigger of shallow convection does not include this additional large-scale vertical velocity term, and shallow cumuli are not allowed to precipitate in the KFB scheme. The entrainment rates are constant with height with a value of $1.3 \times 10^{-4} \mathrm{~m}^{-1}$ for deep convection and a value of $4 \times 10^{-3} \mathrm{~m}^{-1}$ for shallow convection.

Finally, version ECS corresponds to version ECM, but with the standard moist static energy subcloud equilibrium closure for shallow convection replaced by a closure where the cloud-base mass flux is proportional to the convective vertical velocity scale (Grant 2001). The author showed that this closure is appropriate for simulating the diurnal cycle of shallow convection over land, as it provides cloud-base mass fluxes that vary with the surface heat fluxes.

\section{IDEALIZED CASE STUDY}

The ability of the different convection schemes to simulate the diurnal cycle of convection over land is first evaluated using the SCM approach. The SCM represents one grid column of the 3D model that is forced with domain- and time-averaged tendencies of temperature and moisture, and surface fluxes.

\section{(a) Numerical set-up and reference experiment}

The idealized case (Guichard et al. 2004) is derived from a continental midlatitude convective case observed during the Atmospheric Radiation Measurement (ARM) experiment (i.e. the first day of the ARM-Global Energy and Water-cycle Experiment (GEWEX) Cloud System Study (GCSS) Working Group 4 Case 3 subcase A, from 0530 UTC 27 June 1997 to 0530 UTC 28 June 1997; see the intercomparison studies between CRMs by Xu et al. (2002) and between SCMs by Xie et al. (2002)). The present case aims to address the problem of simulating the diurnal cycle of precipitating convection over land (Guichard et al. 2004). The applied large-scale forcing corresponds to the vertical advective tendencies analyzed by Zhang and Lin (1997), and has values of $-0.2 \mathrm{~K} \mathrm{day}^{-1}$ for temperature and $0.16 \mathrm{~g} \mathrm{~kg}^{-1} \mathrm{day}^{-1}$ for moisture, when averaged over the whole tropospheric depth of $15 \mathrm{~km}$ and one diurnal cycle. The surface latent and sensible heat fluxes are specified from observations with the Bowen ratio method. 
In this paper a CRM simulation is used as reference. Full details and further analyses of the CRM data are given in the companion paper by Chaboureau et al. (2004). The reference CRM run was performed with the non-hydrostatic mesoscale model Méso-NH (Lafore et al. 1998) including in particular a 1.5-order turbulence scheme, an interactive radiation parametrization and a prognostic microphysical scheme for 5 precipitating and non-precipitating liquid and solid water categories. The CRM was run with a $2 \mathrm{D}$ domain including 256 horizontal grid points with a spacing of $2 \mathrm{~km}$, and 47 vertical levels between the surface and the model top at $25 \mathrm{~km}$. The model time step is $8 \mathrm{~s}$ and boundary conditions are cyclic. In Chaboureau et al. (2004), the CRM run has been evaluated in terms of convective stability, and planetary boundary-layer (PBL) height evolution, showing that the model is able to reproduce a diurnal cycle of these parameters, as observed. Furthermore, a sensitivity study to the horizontal resolution in two dimensions showed that the present results are robust as no systematic delay in rainfall with decreasing resolution was observed.

The SCM was run with a time step of 20 minutes and the same 60 vertical levels as in the operational GCM. The CRM and SCMs were initialized from an areaaverage sounding and integrated over 4 days, with the domain-averaged horizontal wind components nudged toward the observed values using a relaxation time of 2 hours.

\section{(b) Surface fluxes}

The evolution of the surface precipitation rate over 4 daily cycles is depicted in Fig. 1. The evolution is not exactly cyclic, as the atmospheric state is not in equilibrium with the imposed surface fluxes, which are not allowed to vary in response to surface moistening through precipitation, lower atmospheric cooling/drying by convective downdraughts, and cloud shading. The general picture from Fig. 1 is that the main precipitation peak in the CRM occurs at $15 \mathrm{~h}$, and that in the SCMs, apart from the KFB run, the main precipitation peak occurs about 6 hours earlier. The differences between the three ECMWF model versions (EC, ECM, ECS) is rather small and none of these versions seems to reduce the spurious early morning peak in precipitation in a fundamental way. The KFB run reproduces the CRM results in terms of timing of precipitation, although the amount is significantly overestimated. The main difference from the other schemes is the cloud-base virtual temperature criterion which is modulated with a vertical-velocity dependence. In this case, the vertical velocity effect is about $1.5 \mathrm{~K}$ as the result of a diurnal cycle of about $0.1 \mathrm{~cm}^{-1}$. The vertical velocity forcing is such that it enforces the correct onset of precipitation with the KFB scheme.

In the following, all results are presented in the form of one diurnal cycle that constitutes the average over the 4 diurnal cycles. Figure 2 summarizes the evolution of the observed surface heat fluxes as well as the simulated CAPE, convective inhibition (CIN) and surface precipitation. The surface heat and moisture fluxes display a smooth diurnal evolution with maximum positive values around noon, and slightly negative values during the night (Fig. 2(a)); the Bowen ratio ranges between 0.2 and 0.3 . The surface latent heat flux averaged over a day amounts to $138 \mathrm{~W} \mathrm{~m}^{-2}$, corresponding to an evaporation of $4.8 \mathrm{~mm} \mathrm{day}^{-1}$.

In the CRM, the domain-averaged CAPE of a surface parcel (Fig. 2(b)) and the CIN at the lifting condensation level (Fig. 2(c)) vary in response to the prescribed surface fluxes. Maximum CAPE values of about $1000 \mathrm{~J} \mathrm{~kg}^{-1}$ are attained between 9 and $12 \mathrm{~h}$. The CIN is a maximum during the night, with values of $100 \mathrm{~J} \mathrm{~kg}^{-1}$ dropping down to values of $10 \mathrm{~J} \mathrm{~kg}^{-1}$ at noon. In the CRM, the CIN even vanishes at certain grid points, allowing the convection to trigger (Chaboureau et al. 2004). As a result, the 


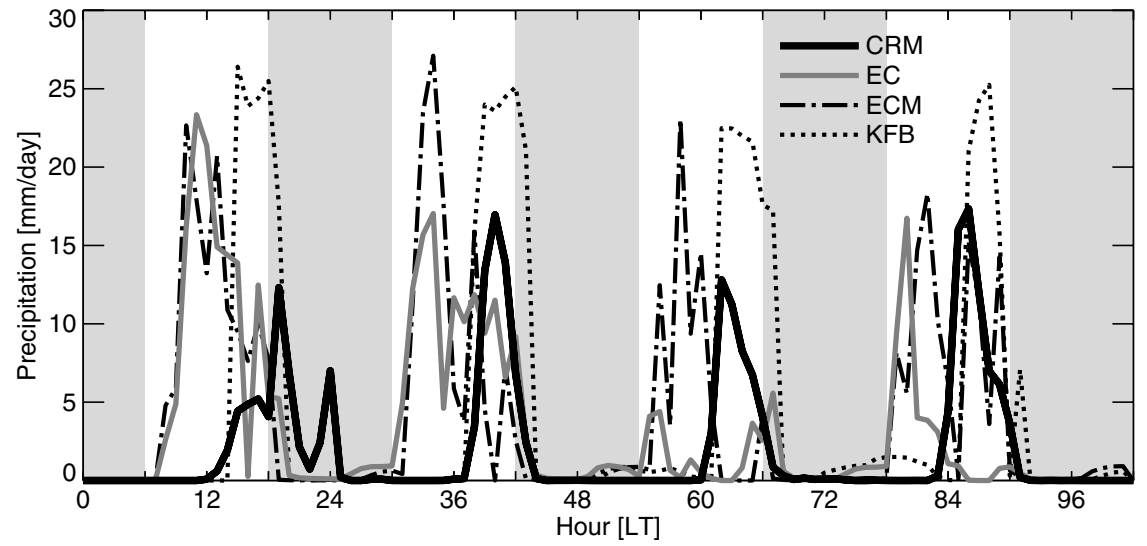

Figure 1. 4-day evolution of the surface precipitation rate for different single-column model runs EC, ECM and KFB (see text) and the cloud-resolving model (CRM). The ECS scheme is very similar to the ECM scheme.
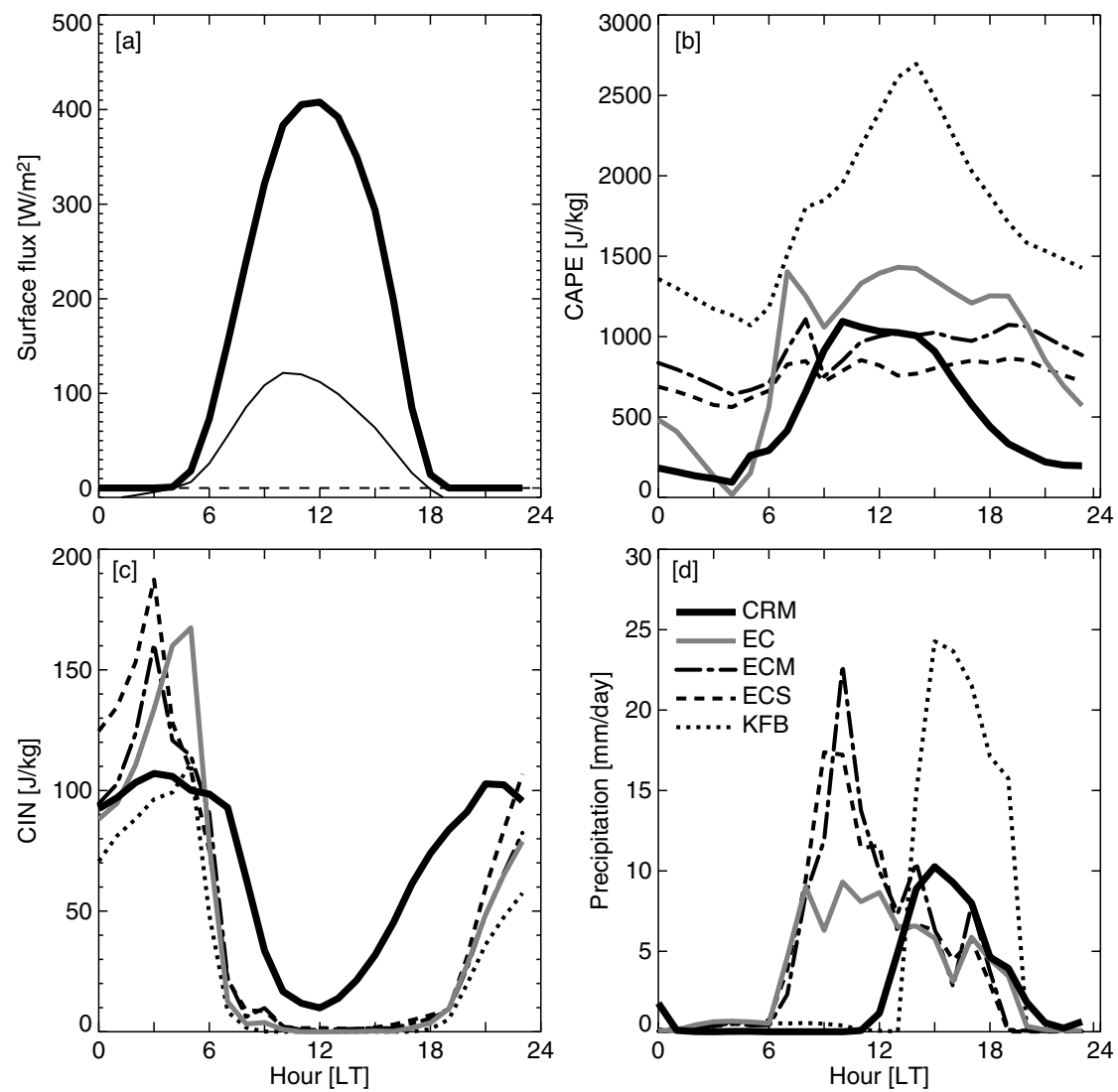

Figure 2. Diurnal cycle (averaged over 4 days of the simulations) of (a) the observed surface latent (thick line) and sensible (thin line) heat fluxes, (b) the convective available potential energy CAPE, (c) the cloud-base convective inhibition CIN, and (d) the surface precipitation rate. (b), (c) and (d) show results from the five models described in the text. 
precipitation in the CRM simulation starts at noon, attains a maximum of $10 \mathrm{~mm} \mathrm{day}^{-1}$ at $15 \mathrm{~h}$, and stops at $21 \mathrm{~h}$ (Fig. 2(d)). The cooling through convective downdraughts is partly responsible for the increase of CIN during the afternoon.

The SCMs are able to reproduce a diurnal cycle of CIN with a nighttime maximum of $100-150 \mathrm{~J} \mathrm{~kg}^{-1}$, but with a minimum value close to zero occurring between 9 and $15 \mathrm{~h}$. The CAPE values differ strongly among the SCMs. The CAPE of the EC run is that of a surface parcel, whereas the CAPE for the remaining SCM runs has been computed for a parcel with mixed-layer properties of the lowest $30 \mathrm{hPa}$, consistent with the trigger procedure. The diurnal variation of CAPE is flattened when using mixed-layer parcels, and it is further flattened when a more active shallow closure is used, as for the ECS run (see discussion on mass-flux profiles in the following subsection). However, the highest CAPE values and strongest diurnal variations of CAPE are produced by the KFB run, where the occurrence of morning convection has been artificially suppressed by a negative temperature perturbation (see Table 1). In all other SCMs, the precipitation (Fig. 2(d)) occurs in conjunction with vanishing CIN and is roughly proportional to the CAPE that is used as a closure for precipitating convection.

It is rather difficult to draw firm conclusions from these results, but it appears that the too early drop in CIN is the main reason for the early onset in EC, ECM and ECS. KFB has the same problem in CIN, but obtains a better timing of precipitation by making use of the imposed diurnal cycle of vertical velocity. The ECM version is smoother in its CAPE evolution, and the shallow convection closure (as in ECS) does not seem to have much impact.

\section{(c) Heating and moistening rates}

The heating and moistening/drying of the atmosphere is examined in Fig. 3 with the aid of time-height sections of cloud condensate, and the apparent heat source and moisture sink $Q_{1}$ and $Q_{2}$, respectively. Following Yanai et al. (1973), the budgets for $Q_{1}$ and $Q_{2}$ are:

$$
\begin{aligned}
& Q_{1}=\frac{\partial s}{\partial t}+A d v(s)=Q_{\mathrm{R}}+L(C-E)-\frac{\partial}{\partial p} \overline{s^{\prime} \omega^{\prime}} \\
& Q_{2}=-L\left\{\frac{\partial q}{\partial t}+A d v(q)\right\}=L(C-E)+L \frac{\partial}{\partial p} \overline{q^{\prime} \omega^{\prime}},
\end{aligned}
$$

where $\partial / \partial t$ is the actual model tendency for the dry static energy $s$ and the specific humidity $q, A d v$ the large-scale advection (forcing) tendency, $Q_{\mathrm{R}}$ the radiative tendency, $L$ the latent heat of vaporization, and $(C-E)$ the net condensation/evaporation rate. The last term on the r.h.s. denotes the vertical transport ( $\omega$ being the vertical velocity in pressure coordinates) due to shallow and deep moist convective motions and turbulent mixing in the subcloud layer. The sign convention in Eqs. (1) and (2) implies that positive values of $Q_{1}$ denote heating and positive values of $Q_{2}$ denote drying.

Due to surface heating and subsequent turbulent transport, the CRM produces between 6 and $9 \mathrm{~h}$ heating and moistening rates of the order of $2 \mathrm{~K} \mathrm{day}^{-1}$ inside the PBL. The first clouds form just after $9 \mathrm{~h}$, leading to further moistening of the upper PBL, but to drying of the subcloud layer. These clouds are a crude representation of shallow cumuli which would be produced in a very high resolution CRM. The onset of deep convection is around $12 \mathrm{~h}$ with cloud tops attaining $5 \mathrm{~km}$. The deep clouds (in an ensemble mean) then grow further to attain their maximum height of about $12.5 \mathrm{~km}$ at $15 \mathrm{~h}$. The onset of precipitation is associated with intense cooling in the lowest $2 \mathrm{~km}$. Finally, after $18 \mathrm{~h}$, convection/precipitation stops and the mid- and upper-level clouds slowly dissipate. 
(a)
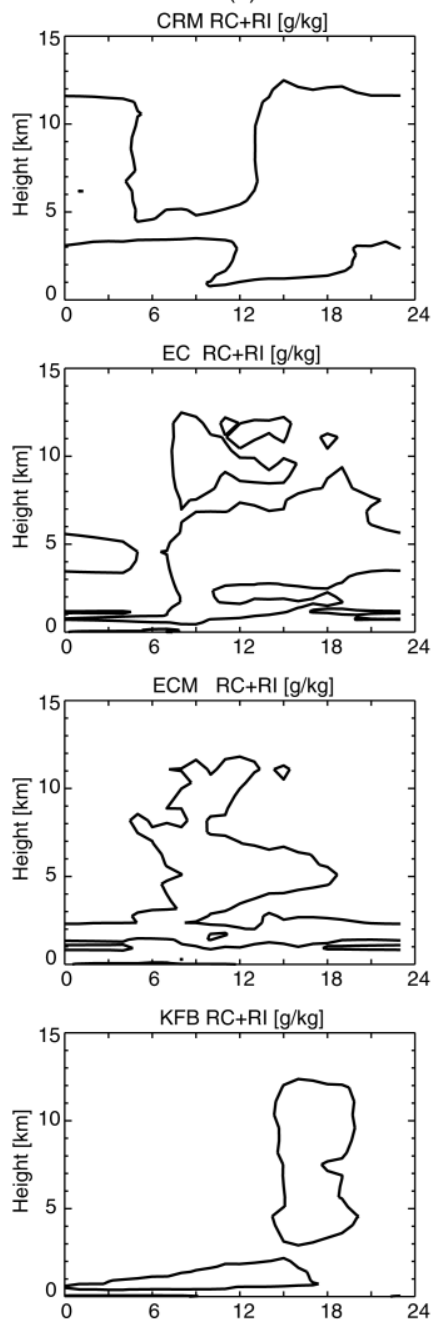

(b)
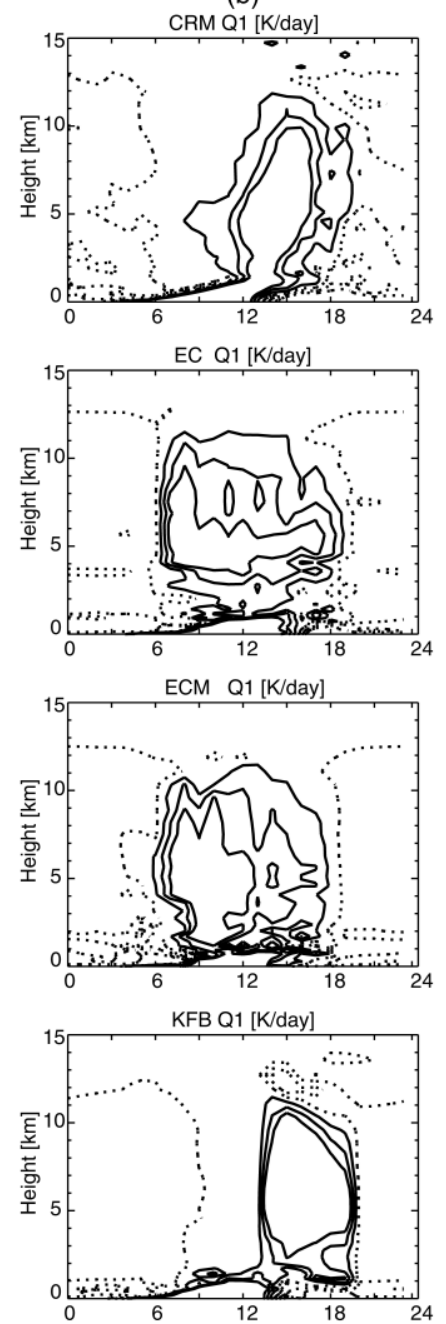

(c)
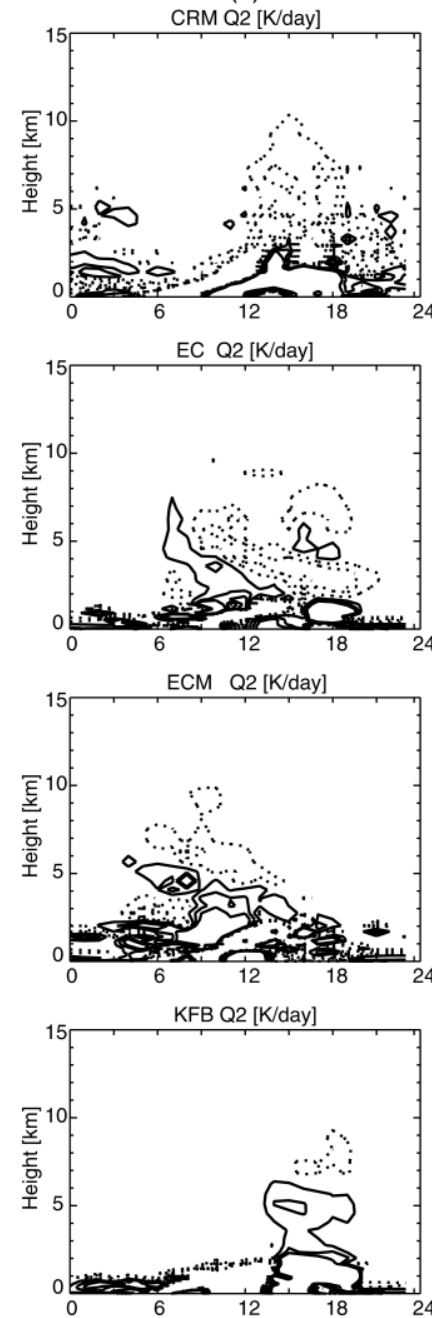

Figure 3. Diurnal cycle, averaged over 4 days of the simulations, of (a) cloud condensate (contours at $0.01 \mathrm{~g} \mathrm{~kg}^{-1}$ intervals), (b) apparent heat source, $Q_{1}$, and (c) apparent moisture sink, $Q_{2}$ (both with contour intervals of $2 \mathrm{~K} \mathrm{day}^{-1}$ from -3 to $5 \mathrm{~K} \mathrm{day}^{-1}$, with dashed (solid) lines representing negative (positive) values). Results are from (top to bottom) the cloud-resolving model (CRM), and the three single-column models EC, ECM and KFB. (ECS results are not shown, because they are very similar to those from ECM.)

The SCMs, using bulk mass-flux schemes with a diagnostic cloud model, are unable to reproduce the gradual growth of the deep precipitating cloud layer. However, the maximum vertical extension of the deep cloud is reasonably reproduced due to the strong link of the cloud scheme to the convective activity through the detrainment of cloud condensate (Tiedtke 1993). The KFB run with suppressed morning convection is able to represent a distinct shallow convective phase in the morning and a deep convective phase in the afternoon, as visible from the cloud field and the evolution of $Q_{1}$.

Finally, as a proxy of the vertical transport, the net convective mass flux averaged over the 4 days of the simulation is displayed in Fig. 4. In the EC, ECM and ECS simulations using the Tiedtke convection scheme, the mass flux peaks at about $800 \mathrm{~m}$ due to strong shallow convective activity. The $w^{*}$ closure with ECS (see Table 1) results 


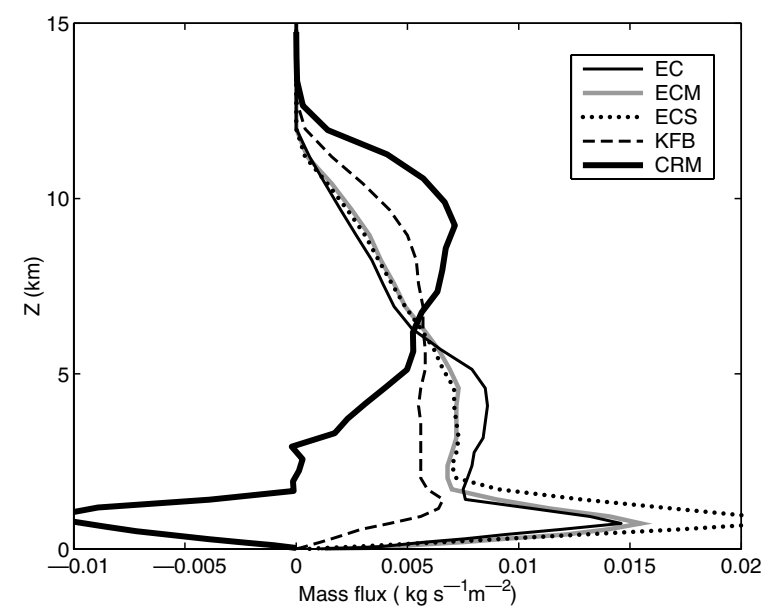

Figure 4. Convective net mass flux averaged over the 4 days of the simulation from the four single-column models (EC, ECM, ECS, KFB, see text) and the cloud-resolving model (CRM).

in more active shallow convection, which is reflected in the higher mass-flux peak at $800 \mathrm{~m}$. Further up, the mass flux follows the specified turbulent entrainment/detrainment profiles that have been optimized for tropical convection (see also mass-flux profiles discussed in Yanai and Johnson (1993)), i.e. a quasi-constant mass-flux profile up to the mid-troposphere, followed by a linear decrease toward the tropopause. Note that in the full GCM, the mid- and upper-level organized entrainment that is based on large-scale moisture convergence would also be active and lead to larger upper-level mass fluxes, but it is negligible in the present SCM runs.

On the other hand, the KFB run with weaker shallow convective activity and vertically constant entrainment/detrainment rates produces a quasi-constant mass-flux profile. The net cloud mass flux as diagnosed from the CRM has also been plotted for comparison. However, as discussed by Yano et al. (2004), there is a fundamental difficulty in diagnosing convective mass fluxes in a CRM. Furthermore, Xu et al. (2002) and Xie et al. (2002) show that the comparison of CRM-derived cloud mass fluxes and convective mass fluxes from parametrizations is even more problematic in the case of continental convection, where the downdraught and updraught mass fluxes are of similar magnitude and the total mass flux in the subcloud layer can even become negative; convective parametrizations generally do not support negative convective mass fluxes. Therefore, the comparison with the diagnosed CRM mass fluxes in Fig. 4 should be regarded as qualitative and does not allow the evaluation of the quality of the cloudbase and subcloud-layer mass fluxes of the SCMs. However, the results in Fig. 4 are consistent with those obtained in Xu et al. (2002) and Xie et al. (2002), where the CRM-derived mass fluxes are smaller than the SCM mass fluxes and become negative below $3 \mathrm{~km}$.

\section{Evaluation AT GLOBAL SCALE}

To evaluate the diurnal cycle in the full ECMWF model, a series of daily global 72-hour forecasts for February 2002 was run at horizontal resolution T511 (40 km), using the EC and ECM model versions, and compared to analyses as well as to satellitederived rainfall rates and surface precipitation observations. Furthermore, a series of 

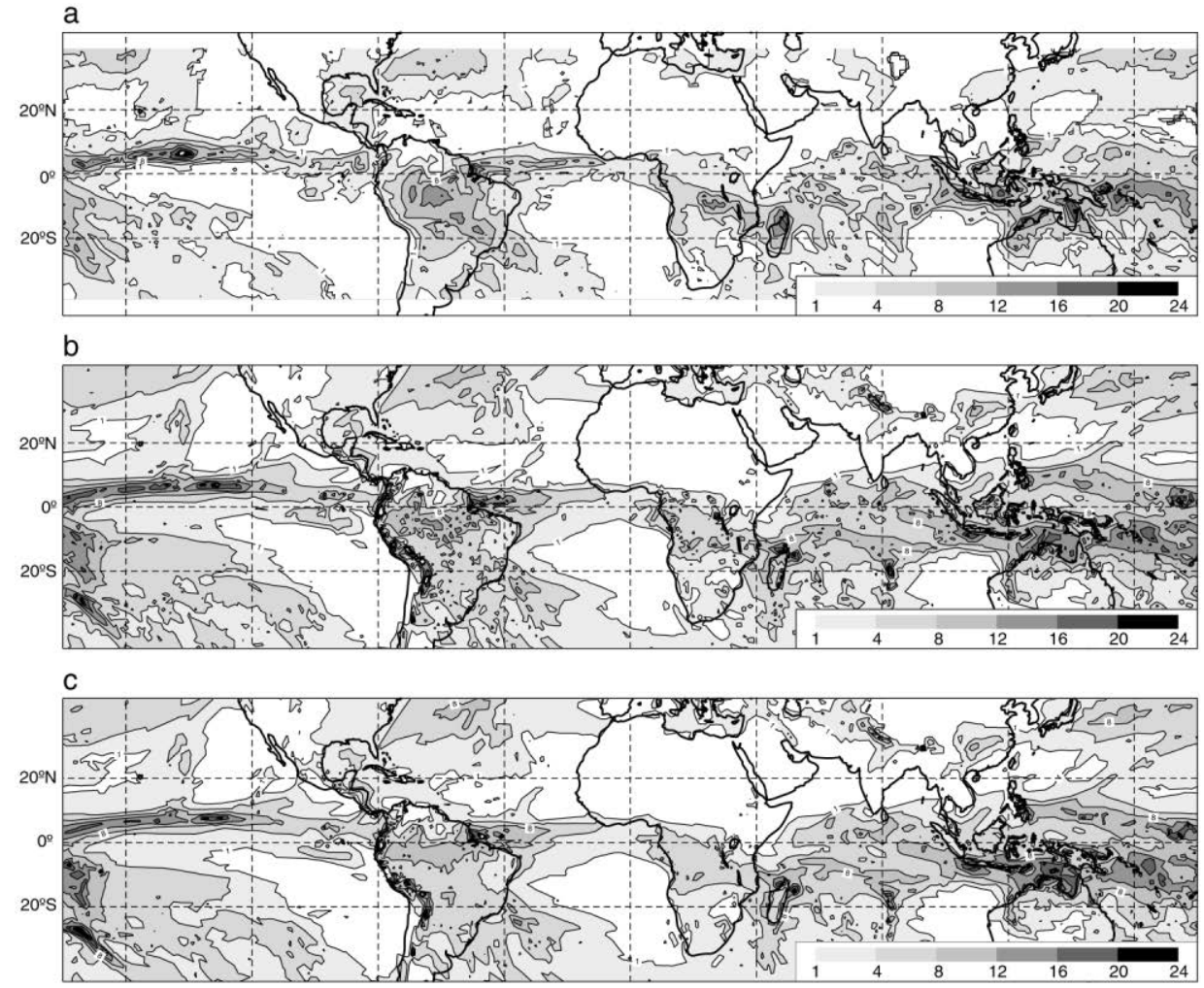

Figure 5. Mean February 2002 rainfall rate $\left(\mathrm{mm} \mathrm{day}^{-1}\right)$ : (a) as observed by TRMM, and from daily T511 24-72 hour forecasts from model version (b) EC and (c) ECM. (The TRMM product 3B43 is derived from microwave and infrared satellite measurements and surface rain-gauge observations, and is available as a monthly mean product at $1^{\circ} \times 1^{\circ}$ resolution.)

longer 40-day integrations at horizontal resolution T159 $(125 \mathrm{~km})$ has been performed with all model versions except ECS. The effect of the modified shallow convection closure was small and is therefore not discussed further.

Figure 5 shows the monthly mean precipitation rate for February 2002, as derived from the TRMM microwave and infrared measurements (product 3B43), as well as the monthly mean precipitation rates from daily T511 24-72 hour forecasts with the EC (operational at that time) and ECM model versions. There is an good overall agreement between the forecasts and the TRMM-derived rain rates. However, compared to the EC model version, ECM produces smoother precipitation fields over South America and Africa and reduces the high precipitation rates over the central Pacific. The TRMM data show somewhat more precipitation over the tropical continents compared to the forecasts, but it is difficult to judge the quality of the TRMM data over land. Finally, note that $62 \%$ of the global precipitation is of the convective type in the model version ECM compared to $52 \%$ in version EC. The main reasons for the difference between EC and ECM are: (i) lifting a mixed-layer parcel in the trigger algorithm of ECM leads to a smoother response due to the vertical averaging of parcel properties, and (ii) the increased precipitation efficiency in the final updraught computation leads to a more active parametrized convection in ECM, leaving less instability to the resolved dynamics. 

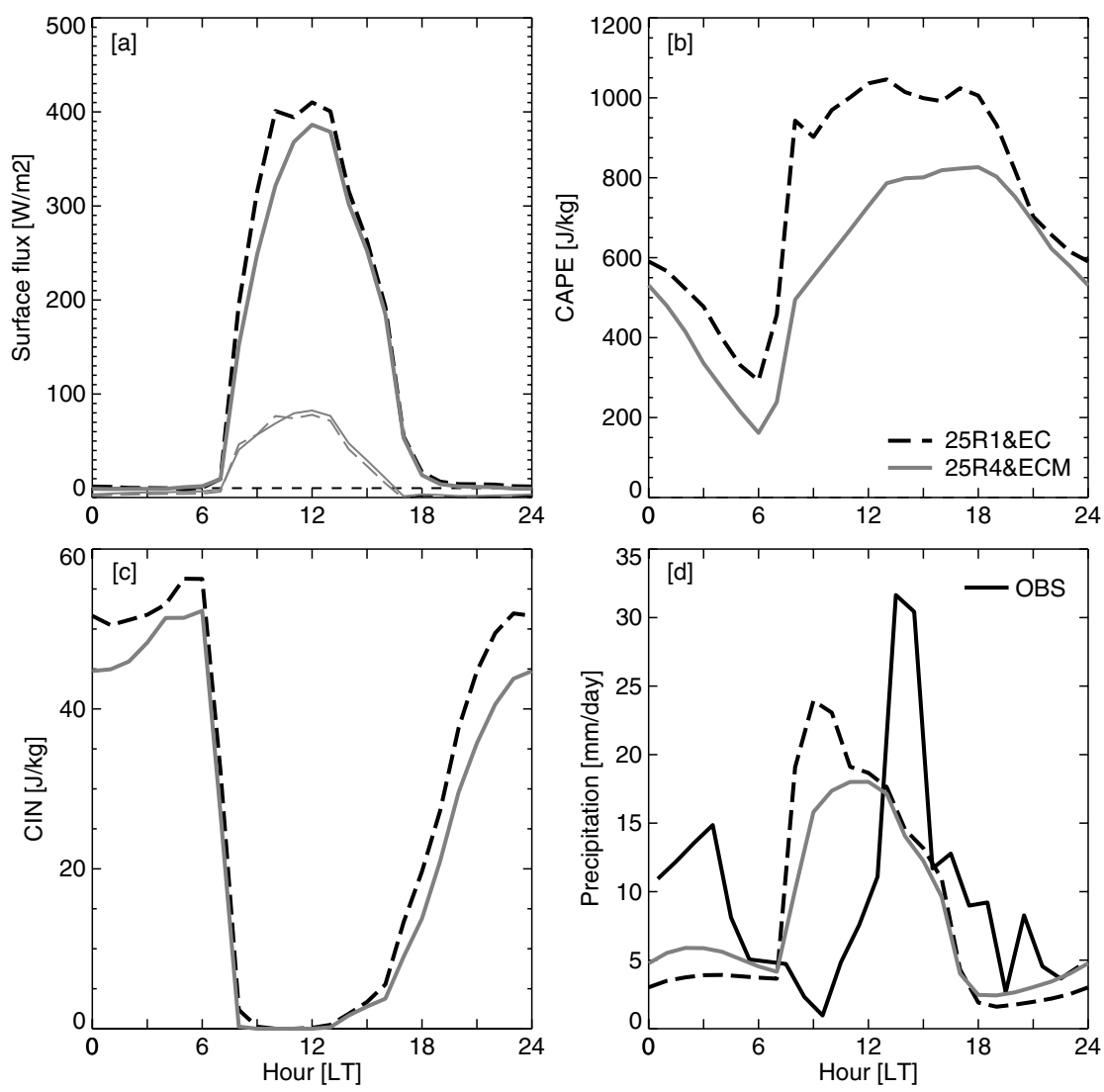

Figure 6. As Fig. 2, but derived from daily T511 24-72 hour forecasts with model versions EC and ECM and averaged over February 2002. The surface rainfall observations for February 1999 collected during the TRMM-LBA campaign are denoted by the solid line in $(\mathrm{d})$.

\section{(a) Amazonia region}

In the following, a budget analysis, similar to the one presented in section 3, is performed for the south-western Amazon (the sub-basin of the Madiera river), where the daily continental rainfall is at a maximum in February and undergoes strong diurnal variations (Betts and Jakob 2002b; Mapes et al. 2003). Also, surface rainfall observations from rain-gauges and radar are available within this basin for a region in Rondonia. These were collected during the Large-Scale Biosphere-Atmosphere Experiment (LBA) in 1999 to calibrate the TRMM satellite precipitation estimates (Silva Dias et al. 2002).

The average diurnal cycle of the surface heat fluxes, precipitation, CAPE and CIN as obtained from daily 24-72 hour forecasts with model versions EC and ECM are plotted in Fig. 6. Increased early morning cloud cover (not shown) in the ECM version leads to a drop of the surface latent heat flux. The behaviour of the diurnal cycles of CAPE, CIN and precipitation is remarkably similar to the diurnal cycles obtained in the idealized midlatitude case study (Fig. 2). The morning increase of CAPE, the drop in $\mathrm{CIN}$ and the onset of precipitation are all coupled to the diurnal cycle of the surface fluxes. In the 3D simulations, averaged over a river basin, the ECM version produces a smoother daily cycle of rainfall. ECM is a clear improvement over the EC version, because it does not have the spurious precipitation peak shortly after sunrise. However, 
as seen in Fig. 5, the removal of the early morning peak has reduced the total rainfall. The precipitation peak in ECM still precedes the observed afternoon peak by about two hours.

The main reason for the smooth precipitation evolution in ECM (which lacks the strong morning peak of EC) is that CAPE is reduced (see Fig. 2(b)), both by the use of $30 \mathrm{hPa}$ 'mixed-layer' properties and to a lesser extent by the slightly larger entrainment rate (see Table 1), which also affects the moist adiabat of the ascending parcels. It turns out that diagnosing CAPE in the ECM model using a surface parcel (not shown), values are obtained that are very close to those from EC.

To further analyse the mean vertical structure and quality of the forecasts, the monthly mean forecast temperature and dew point soundings for Manaus, located on the Amazon river at $3^{\circ} \mathrm{S}, 60^{\circ} \mathrm{W}$, are compared in Fig. 7 with monthly mean profiles from the 40-year European Reanalysis project (ERA40) and available radiosonde data. Generally, there is a close agreement between the forecast, analyzed and measured profiles at 12 and 00 UTC ( 8 and $20 \mathrm{~h})$. The ECM version closely fits the analysis, except at 12 UTC where a negative bias of $1-2 \mathrm{~K}$ is present in the lowest levels (due to early morning low cloud cover, not shown), whereas the EC forecasts develop at 12 UTC a slightly warmer mid-tropospheric temperature profile and a mid-tropospheric dry bias of $1-2 \mathrm{~K}$ in dewpoint temperature with respect to the analysis. Note that the forecast free-tropospheric tropical profiles depend on parameters of the convection scheme such as cloud-base properties of the convective parcel, entrainment rate and microphysics. The main difference between the radiosonde measurements and the analyses/forecasts is a warmer boundary layer in the radiosonde measurements, characterizing an atmosphere that is neutral or unstable with respect to moist ascent. The radiosonde data also indicate a drier upper troposphere with a relative humidity that varies between 12 and 00 UTC. However, one must be cautious with the interpretation of the data as radiosonde biases can be substantial for moisture.

\section{(b) Global Hovmüller diagrams}

This section compares global Hovmüller diagrams (longitude versus local time) of the T511 24-72 hours precipitation forecasts with 3-hourly TRMM-derived rain rates from the experimental product 3B42. The model and observational data have been averaged over the tropical latitude band between $20^{\circ} \mathrm{S}$ and $20^{\circ} \mathrm{N}$, and are shown in Fig. 8. In addition, long-range 40-day integrations at resolution T159 (125 km) were also run to evaluate the influence of model drift on the representation of the diurnal cycle. The global Hovmüller diagrams for the long integrations are displayed in Fig. 9.

The Hovmüller plots in Fig. 8 show distinct maximum precipitation rates over Africa $\left(0-30^{\circ} \mathrm{E}\right)$, India, south-east Asia and the so-called maritime continent (90$\left.180^{\circ} \mathrm{E}\right)$, and Amazonia $\left(270-300^{\circ} \mathrm{E}\right)$. Distinct daytime precipitation maxima can be identified over Africa and South America with averaged maxima between 6 and $9 \mathrm{~mm}$ day $^{-1}$ that occur at $9 \mathrm{~h}$ for EC, $12 \mathrm{~h}$ for ECM, and at $15 \mathrm{~h}$ in the TRMM-based precipitation retrievals (Fig. 8(c)). The TRMM observations also contain a distinct nighttime precipitation peak at $3 \mathrm{~h}$ for Africa and Amazonia that is also weakly present in the ECM forecasts. There is a remarkable consistency in the diurnal cycle of the rainfall rates over South America between the TRMM-derived rain rates and the surface observations for a small region in Rondonia (Fig. 6(d)). The situation for the maritime continent is more subtle, as the forecasts produce more and quasi-continuous precipitation in the region $120-150^{\circ} \mathrm{E}$ that is reinforced during late nighttime, though the distinct afternoon and late night precipitation maxima are also supported by the TRMM observations. As discussed in Chen and Houze (1997), the late nighttime precipitation 
(a)

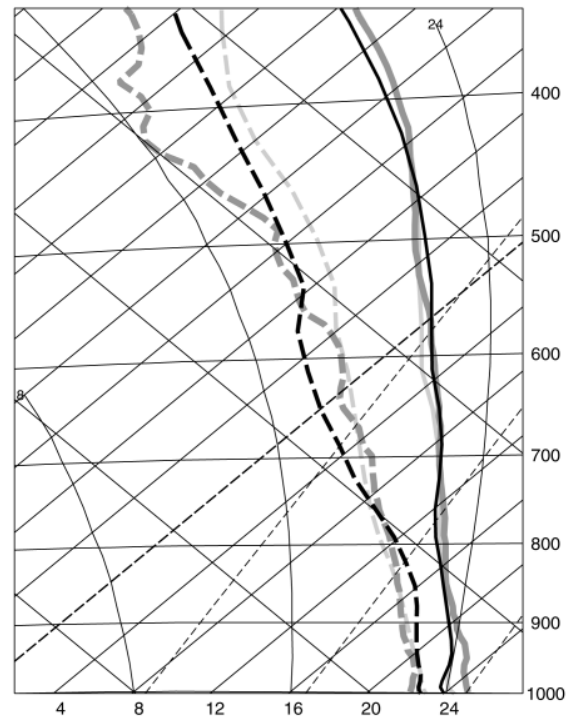

(c)

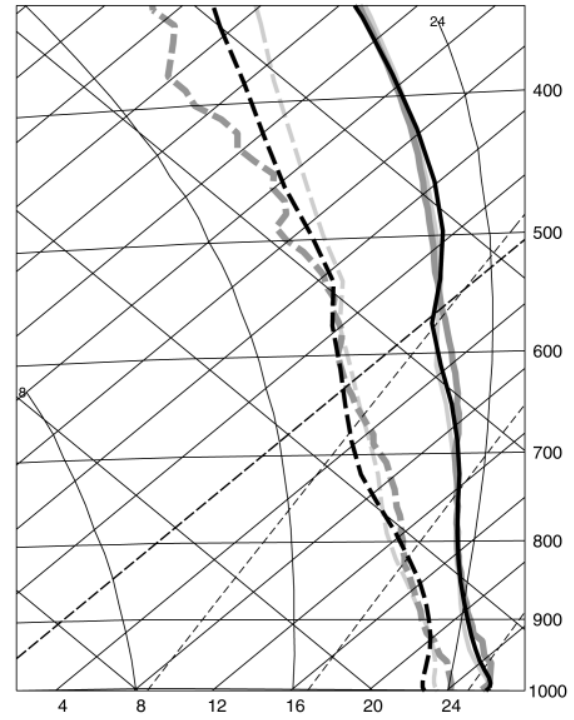

(b)

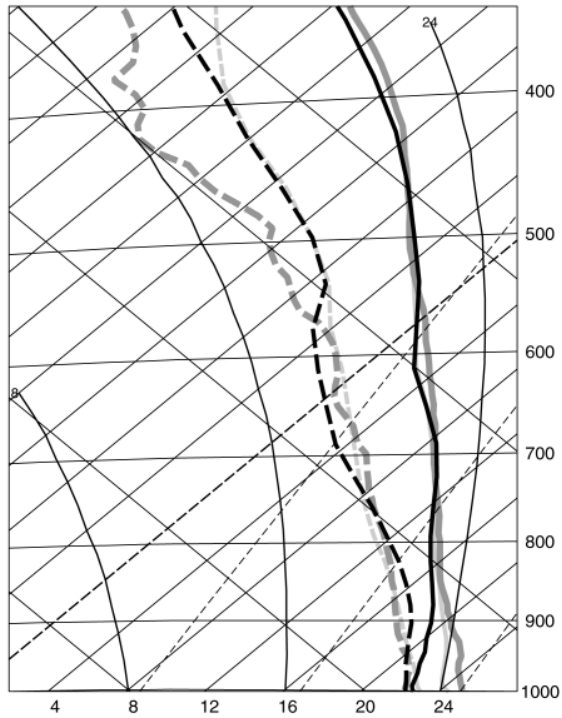

(d)

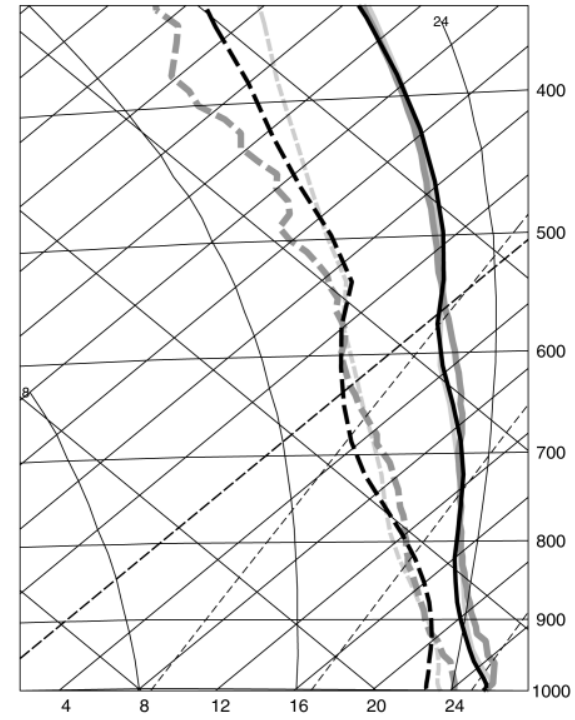

Figure 7. Mean temperature (solid) and dewpoint (dashed) soundings for February 2002 for Manaus, Brazil, at 12 UTC (8 h) from 72-hour daily forecasts using (a) model EC and (b) model ECM. (c) and (d): as (a) and (b), but for 00 UTC $(20 \mathrm{~h})$. Results from models are shown as black, ERA40 reanalyses as light grey, and radiosonde ascents as dark grey.

maximum over the tropical Pacific can be partly explained by differential heating between the cloud-top and cloud-base levels, and the cloud and its environment, but other factors like diurnal variations in sea surface temperature, the life cycle of tropical cloud systems and the interaction with westward propagating gravity waves also play a role.

The present findings for a one-month series of daily short-range high-resolution forecasts are also confirmed in Fig. 9 from single long-range 40-day integrations at horizontal resolution T159. Again, in the EC run the precipitation peaks at $9 \mathrm{~h}$ over 

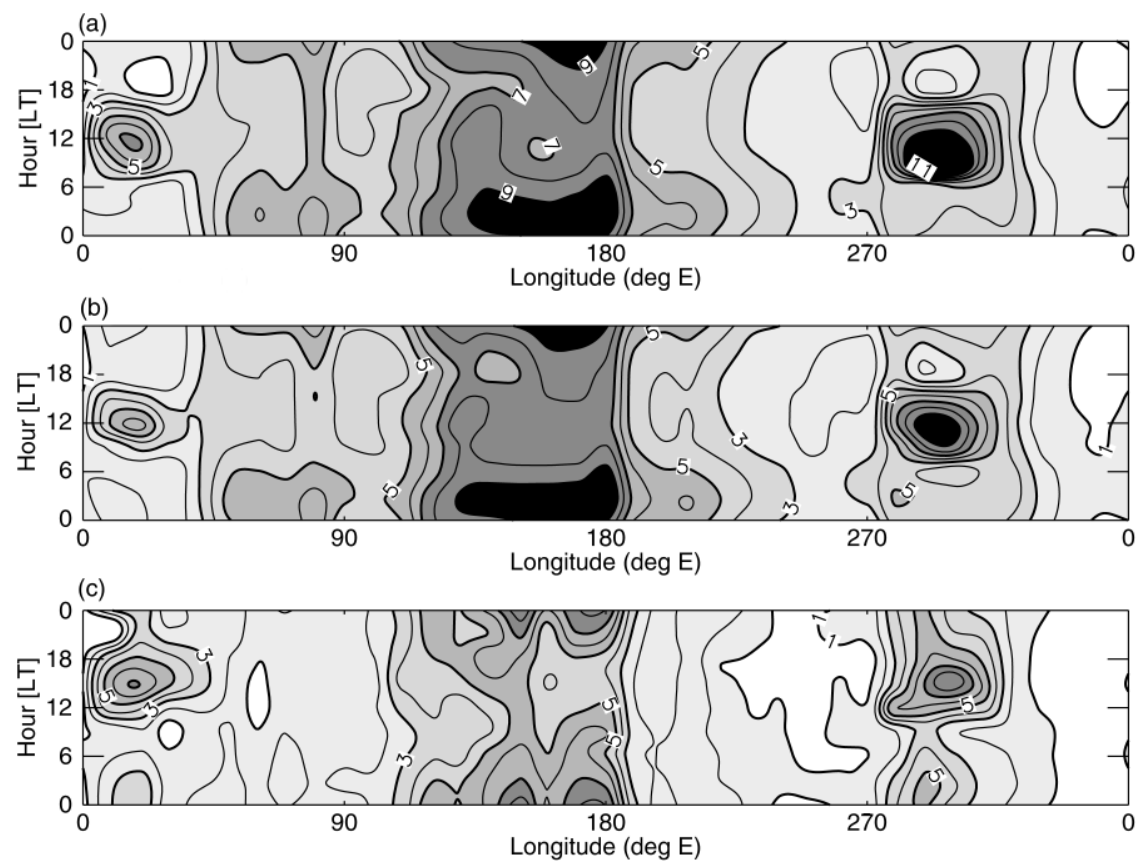

Figure 8. Global Hovmüller diagrams of the diurnal cycle of precipitation $\left(\mathrm{mm} \mathrm{day}^{-1}\right)$ for February 2002, averaged between $20^{\circ} \mathrm{S}$ and $20^{\circ} \mathrm{N}$, as obtained from (a) 24-72 hour forecasts at horizontal resolution T511 with model version EC, (b) as (a) with model version ECM, and (c) TRMM measurements. The time resolution of the data is 3 hours.
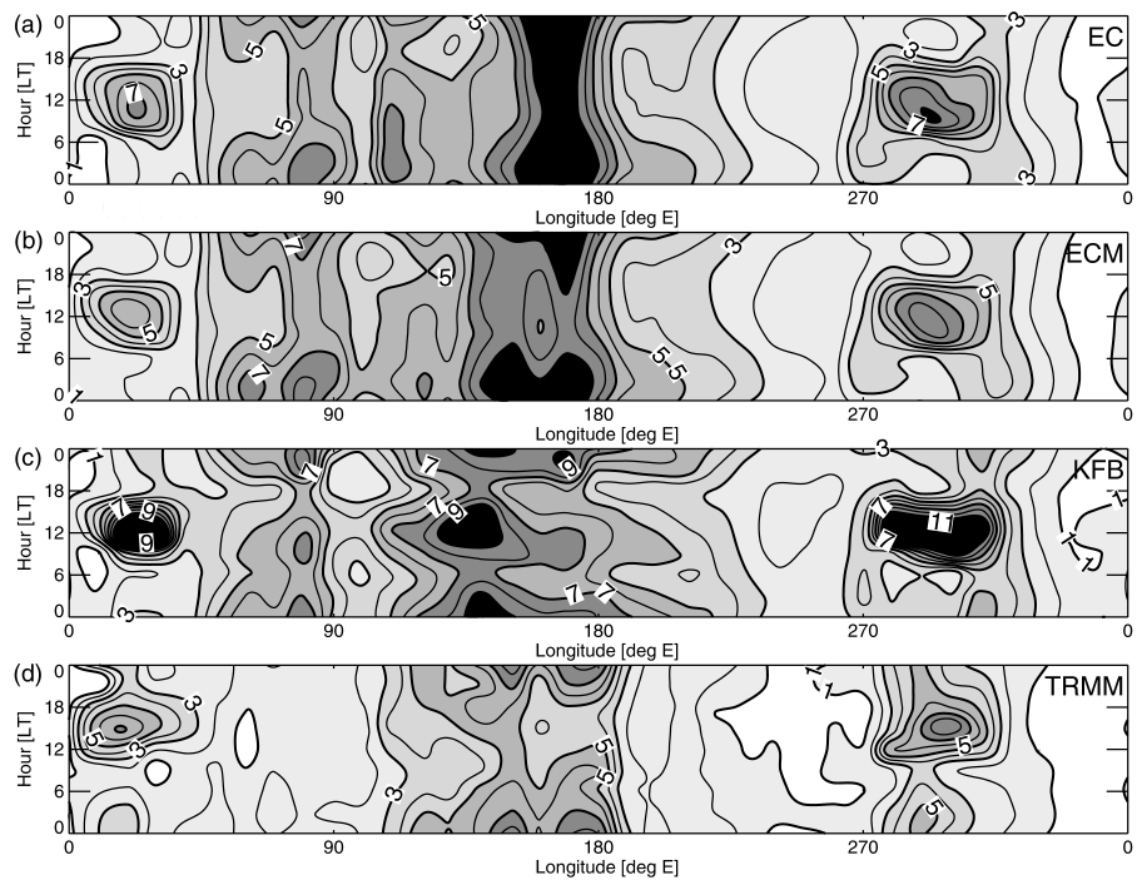

Figure 9. As Fig. 8, but from 40-day integrations at horizontal resolution T159 with model versions (a) EC, (b) ECM, and (c) KFB, as used in the idealized case study. (d) shows the TRMM measurements. 
South America and Africa compared to $12 \mathrm{~h}$ in model version ECM. The latter also better reproduces the diurnal cycle over the tropical western Pacific with a distinct daytime minimum and late nighttime precipitation maximum. However, there is still an overestimation of precipitation over the Indian Ocean. The results with the KFB version using a different bulk mass-flux convection parametrization (see Table 1), with the convective trigger linked to the large-scale velocity field, are also shown in Fig. 9. In this run the diurnal cycle over the continents is more pronounced, in agreement with the observations, but the precipitation maxima are overestimated, and the coupling to the vertical velocity field produces a spurious precipitation maximum near noon over the maritime continent.

\section{SUMMARY AND CONCLUSIONS}

The problem of the representation of the diurnal cycle of convective precipitation over land has been examined, especially the problem of a too early triggering of precipitation after sunrise that is shared by many GCMs.

In the context of the EUROCS project, the problem has been first addressed with the aid of an idealized midlatitude case study using observed surface and large-scale forcings. A SCM version of the ECMWF global forecast model has been run with various versions of bulk mass-flux convection parametrizations and the results have been compared to a parallel CRM simulation. An analysis of the heating/moistening phases for the idealized convective case pointed out three important stages in the diurnal cycle, i.e. a moistening of the upper boundary layer through shallow convective transport during the morning, followed by a growth (in an ensemble sense) of deep convection between noon and $15 \mathrm{~h}$, and subsequent intense precipitation and boundarylayer stabilization by convective downdraughts. The SCM runs mainly produced a morning precipitation peak at $9 \mathrm{~h}$, except a version where the early morning peak was artificially suppressed by a temperature perturbation proportional to the sign of the largescale vertical velocity. Therefore, the precipitation peak at $15 \mathrm{~h}$ present in the CRM could not be reproduced, partly because stationary bulk convection schemes are unable to reproduce a 3-hourly growth of deep clouds from the cumulus congestus stage to a deep precipitating stage (Chaboureau et al. 2004; Guichard et al. 2004). An alternative shallow convection closure leading to bigger mass fluxes does not have a substantial impact on the morning deepening of convection and on the onset of precipitation. Further diagnostics show that the convection in the SCMs is in phase with CIN and CAPE. It is also shown that defining appropriate cloud base (subcloud) properties of the ascending parcel and entrainment rates are important in order to represent an appropriate phase and amplitude of the CAPE.

In the second part of the paper the diurnal cycle has been investigated at global scale for February 2002 using ensembles of daily 72-hour global forecasts at horizontal resolution T511 $(40 \mathrm{~km})$, and single 40-day integrations at horizontal resolution T159 $(125 \mathrm{~km})$. Results are compared to rain rates derived from TRMM satellite measurements and available surface observations. The focus was on the Amazon basin and tropical Africa, where the diurnal cycle of convection over land is most pronounced during that season. For these regions, both the TRMM data and surface observations indicate maximum precipitation rates occurring at $15 \mathrm{~h}$. In the model version EC (operational until January 2003), maximum precipitation rates occur at $9 \mathrm{~h}$. However, the model version ECM with an improved convective trigger procedure and slightly larger entrainment rates (see description in section 2) produces a smooth daily cycle of precipitation (with maximum intensities at $12 \mathrm{~h}$ ) that is in phase with the solar cycle and the surface fluxes. 
Furthermore, in model version ECM, $62 \%$ of the global precipitation is of the convective type compared to $52 \%$ in model version EC. The former model version also produced the smallest overall biases compared to the ERA 40-year reanalysis, and significantly improved the northern hemisphere spring/summer height and wind scores as well as the tropical wind scores (not shown). The ECM model version became operational at ECMWF on 14 January 2003.

Nevertheless, further model developments are necessary to match the observed precipitation peak at $15 \mathrm{~h}$. Bulk mass-flux convection schemes with their diagnostic cloud model have obvious limitations in representing weakly forced multi-modal convection. Possible candidates for improvement are an increase in the mid-tropospheric entrainment rate (which would also increase the still poorly represented sensitivity to environmental humidity, see Derbyshire et al. (2004)), and an improved shallow convective closure that strongly ventilates the morning boundary layer. Both measures would reduce the morning CAPE, and therefore affect the convective precipitation.

Finally, it is stressed that the impact of changes to the convection parametrization which improve the diurnal cycle must be carefully evaluated in a global forecast model, as such changes might significantly impact on the partitioning between convective and stratiform precipitation in the model, the quality of the forecasts and the tropical climate and variability.

\section{ACKNOWLEDGEMENTS}

This research was supported by the EUROCS project, funded by the European Commission under contract EVK2-1999-00322. We are grateful for the suggestions by two anonymous reviewers, as well as to Pedro Viterbo and Adrian Tompkins for making available data-processing software, to Fernando Li and Rob Hine for graphics support, and to the precipitation research team of Dr. Robert Adler at the Laboratory for Atmospheres of the NASA Goddard Space Flight Center for posting the TRMMbased precipitation retrievals on the web. Alan Betts is supported by NASA under grant NAS5-11578 and by the National Science Foundation under grant ATM-9988618.

Bechtold, P., Bazile, E.,

Guichard, F., Mascart, P. and Richard, E.

Betts, A. K. and Jakob, C.

Betts, A. K., Viterbo, P. and

Wood, E.

Chaboureau, J.-P., Guichard, F.,

Redelsperger, J.-L. and

Lafore, J.-P.

Chen, S. S. and Houze, R. A.

Dai, A., Giorgi, F. and

Trenberth, K. E.

\section{REFERENCES}

2001 A mass flux convection scheme for regional and global models. Q. J. R. Meteorol. Soc., 127, 869-886

2002a Evaluation of the diurnal cycle of precipitation, surface thermodynamics and surface fluxes in the ECMWF model using LBA data. J. Geophys. Res., 107, 8045, doi: 10.1029/2001JD000427

2002b Study of diurnal cycle of convective precipitation over Amazonia using a single column model. J. Geophys. Res., 107, 4732, doi: 10.1029/2002JD002264

1998 Surface energy and water balance for the Arkansas-Red river basin from the ECMWF reanalysis. J. Climate, 11, 28812897

2004 The role of stability and moisture in the diurnal cycle of convection over land. Q. J. R. Meteorol. Soc., 130, 3105-3117

1997 Diurnal variations and life-cycle of deep convective systems over the tropical Pacific warm pool. Q. J. R. Meteorol. Soc., 123, 367-388

1999 Observed and model simulated precipitation diurnal cycle over the contiguous United States. J. Geophys. Res., 104, 63776402 
Derbyshire, S. H., Beau, I.,

Bechtold, P., Grandpeix, J.-Y.,

Piriou, J.-M.,

Redelsperger, J.-L. and

Soares, P. M. M.

Grant, A. L. M.

Gregory, D., Morcrette, J.-J., Jakob, C., Beljaars, A. M. and Stockdale, T.

Guichard, F., Petch, J. C.,

Redelsperger, J.-L.,

Bechtold, P.,

Chaboureau, J.-P., Cheinet, S., Grabowski, W., Grenier, H.,

Jones, C. G., Köhler, M.,

Piriou, J.-M., Tailleux, R. and

Tomasini, M.

Jakob, C. and Siebesma, A. P.

Janowiak, J. E., Arkin, P. A. and Morrissey, M.

Kain, J. S. and Fritsch, J. M.

Lafore, J.-P., Stein, J., Asencio, N., Bougeault, P., Ducrocq, V., Duron, J., Fischer, C.,

Héreil, P., Mascart, P.,

Masson, V., Pinty, J.-P.,

Redelsperger, J.-L.,

Richard, E. and

Vilà-Guerau de Arellano, J.

Lin, X., Randall, D. A. and

Fowler, L. D.

Mapes, B. E., Warner, T. T., Xu, M. 2003 and Negri, A. J.

Silva Dias, M. A. F., Rutledge, S.,

Kabat, P., Silva Dias, P. L.,

Nobre, C., Gish, G.,

Dolman, A. J., Zipser, E.,

Garstang, M., Manzi, A. O.,

Fuentes, J. D., Rocha, H. R.,

Marengo, J., Plana-Fattori, A.,

Sá, L. D. A., Alvalá, R. C. S.,

Andreae, M. O., Artaxo, P.,

Gielow, R. and Gatti, L.

Slingo, J. M., Sperber, K. R.,

Morcrette, J. J. and

Potter, G. L.

Tiedtke, $\mathrm{M}$.

2002

1992

1989

1993

Wallace, J. M.

2001

2000

2004

2003

1994

1993

1998

2000

Sensitivity of moist convection to environmental humidity. Q. J. R. Meteorol. Soc., 130, 3055-3079

Diurnal variability of the hydrologic cycle and radiative fluxes: Comparisons between observations and a GCM. J. Climate, 13, 4159-4179

Diurnal patterns of rainfall in northwestern South America. Part I: observations and context. Mon. Weather Rev., 131, 799-812

Clouds and rain processes in a biosphere atmosphere interaction context in the Amazon region. J. Geophys. Res., 107, 8072, doi: 10.1029/2001JD000335

Analysis of the temporal behavior of convection in the tropics of the European Centre for Medium-Range Weather Forecasts model. J. Geophys. Res., 97, 18119-18135

A comprehensive mass flux scheme for cumulus parametrization in large-scale models. Mon. Weather Rev., 117, 1779-1800

Representation of clouds in large-scale models. Mon. Weather Rev., 121, 3040-3061

1975 Diurnal variations in precipitation and thunderstorm frequency over the conterminous United States. Mon. Weather Rev., 103, 406-419 
Xie, S., Cederwall, R. T., Xu, K.-M., Bechtold, P., Cripe, D. G., Del Genio, A. D., Ghan, S. J., Gregory, D., Hack, J. J., Iacobellis, S. F., Klein, S. A., Krueger, S. K., Lohmann, U., Petch, J. C., Randall, D. A.,

Rotstayn, L. D.,

Somerville, R. C. J.,

Sud, Y. C., von Salzen, K., Walker, G. K., Wolf, A., Yio, J. J., Zhang, G. and Zhang, M.

Xu, K.-M., Cederwall, R. T., Donner, L. J., Grabowski, W. W., Guichard, F., Johnson, D. E., Khairoutdinov, M., Krueger, S. K., Petch, J. C., Randall, D. A., Seman, C. J., Tao, W.-K., Wang, D., Xie, S. C., Yio, J. J. and Zhang, $\mathrm{M}$.

Yanai, M. and Johnson, R. H.

Yanai, M., Esbendsen, S. K. and Chuh, J.-H.

Yang, G.-Y. and Slingo, J.

Yano, J.-I., Guichard, F., Lafore, J.-P.,

Redelsperger, J.-L. and Bechtold, P.

Zhang, M. H. and Lin, J. L.
Intercomparison and evaluation of cumulus parametrizations under summertime midlatitude continental conditions. Q. J. R. Meteorol. Soc., 128, 1095-1135

2002

An intercomparison of cloud-resolving models with the ARM summer 1997 IOP data. Q. J. R. Meteorol. Soc., 128, 593624

1993 Impact of cumulus convection on thermodynamic fields. Meteorol. Monogr., 46, 39-62

1973 Determination of bulk properties of tropical cloud clusters from large-scale heat and moisture budgets. J. Atmos. Sci., 30, 611-627

2001 The diurnal cycle in the tropics. Mon. Weather Rev., 129, 784-801

2004 Estimation of mass fluxes for cumulus parameterizations from high-resolution spatial data. J. Atmos. Sci., 61, 829-842

1997 Constrained variational analysis of sounding data based on column-integrated budgets of mass, heat, moisture, and momentum: Approach and application to ARM measurements. J. Atmos. Sci., 54, 1503-1524 